\title{
MicroRNA-9 suppresses the sensitivity of CNE2 cells to ultraviolet radiation
}

\author{
CHAO-PAN ZHENG ${ }^{1,2^{*}}$, LING HAN ${ }^{1,2^{*}}$, WEI-JIAN HOU ${ }^{1}$, JUN TANG $^{3}$, \\ YI-HUI WEN $^{1}$, RAN FU ${ }^{1}$, YUE-JIAN WANG ${ }^{3}$ and WEI-PING WEN ${ }^{1}$ \\ ${ }^{1}$ Department of Otorhinolaryngology, The First Affiliated Hospital and Otorhinolaryngology Institute, Sun Yat-Sen University, \\ Guangzhou, Guangdong 510080; ${ }^{2}$ Department of Otolaryngology, Shenzhen People's Hospital, Shenzhen, Guangdong 518100; \\ ${ }^{3}$ Department of Otolaryngology, First People's Hospital, Foshan, Guangdong 528000, P.R. China
}

Received February 24, 2014; Accepted March 9, 2015

DOI: $10.3892 / \mathrm{mmr} .2015 .3622$

\begin{abstract}
MicroRNA (miR)-9 has been demonstrated to regulate the radiosensitivity of tumor cells. In the present study, the mechanism by which miR-9 modulates the sensitivity of nasopharyngeal carcinoma (NPC) cells to ultraviolet (UV) radiation was investigated. The results demonstrated that exposure of NPC cells to UV light resulted in a significant increase in the expression of miR-9, and that CNE2 cells overexpressing miR-9 exhibited reduced levels of DNA damage and increased levels of total glutathione upon UV exposure. Accordingly, the inhibition of the expression of miR-9 promoted UV-induced DNA damage and apoptosis. Although miR-9 inhibited the expression of E-cadherin in the CNE2 cells and increased their resistance to UV radiation, the use of small interfering RNA to inhibit the expression of E-cadherin was not sufficient to decrease the radiosensitivity of the NPC cells. These data demonstrated that miR-9 did not modulate the sensitivity of the CNE2 cells to UV radiation through E-cadherin, but suggested that miR-9 regulated radiosensitivity through its effects on glutathione. These findings suggest that miR-9 may be a potential target for modulating the radiosensitivity of NPC cells.
\end{abstract}

Correspondence to: Dr Wei-Ping Wen, Department of Otorhinolaryngology, The First Affiliated Hospital and Otorhinolaryngology Institute, Sun Yat-Sen University, 58 Zhongshan Road, Guangzhou, Guangdong 510080, P.R. China

E-mail: wenwp@mail.sysu.edu.cn

Dr Yue-Jian Wang, Department of Otolaryngology, First People's Hospital, 81 South Road North, Foshan, Guangdong 528000, P.R. China

E-mail: szrment@163.com

${ }^{*}$ Contributed equally

Key words: microRNA-9, radiosensitivity, CNE2, E-cadherin, ultraviolet rays

\section{Introduction}

Radiotherapy is an important modality used for the treatment of nasopharyngeal carcinoma (NPC). The prognosis of 5-year survival for patients with NPC who have received irradiation treatment has not improved, at least in part, due to the resistance of NPC cells to radiation $(1,2)$. Various mechanisms regulating the radiosensitivity of tumor cells have been suggested, including the induction of DNA damage by reactive oxygen species (ROS) (3) and resistance, mediated by the epithelial-mesenchymal transition (EMT) (4).

MicroRNAs (miRNAs) are endogenous, non-coding RNA molecules, which suppress the expression of target genes by binding to 3 ' untranslated regions. miRNAs provide suitable therapeutic targets, which regulate a number of complex biological processes (5). Previous studies have demonstrated the effects of ionizing radiation on the expression levels of miRNAs, and the radiosensitivity of tumor cells has been demonstrated to be regulated by miRNAs in vitro $(6,7)$. In addition, the expression levels of miRNAs have been reported to be altered by ROS in cells, which have been exposed to ionizing radiation (8). Although the overexpression of miR-9 and let-7 g have been observed to decrease the surviving fraction of $\gamma$-irradiated cells and increased the sensitivity to ionizing radiation in H1299 cells (9), our previous study demonstrated that inhibition of the expression of miR-9 promoted the ultraviolet (UV)-induced production of ROS, DNA damage and apoptosis in NPC cells $(10,11)$. To examine the mechanism underlying radiosensitivity in NPC, the present study investigated whether miR-9 suppresses the sensitivity of NPC cells to UV through UV-induced ROS damage.

miRNAs regulate the progression of cancer by targeting various messenger RNAs with cancer-associated functions. The EMT has been implicated in the increased resistance to radiotherapy and downregulation of the expression of E-cadherin associated with EMT, and has also been demonstrated to promote resistance to radiation therapy in human tumor cells in vitro $(4,5)$. It has been suggested that the decreased expression of E-cadherin is associated with advanced disease and poor survival rates in patients with NPC, and that altered expression levels of E-cadherin may affect the 
prognosis of patients with NPC $(12,13)$. miR-9 directly targets E-cadherin mRNA and thereby regulates cell motility and the invasiveness of breast cancer cells (14). Whether miR-9 modulates the sensitivity of NPC cells to UV radiation by regulating E-cadherin remains to be elucidated.

The present study investigated changes in the expression levels of miR-9 in different NPC cell lines following exposure to UV radiation, to determine the mechanism underlying the effects of miR-9 on radiosensitivity, examine the potential role of E-cadherin, and improve current understanding of the responsiveness of NPC cells to UV radiation.

\section{Materials and methods}

Cell lines and chemicals. The CNE1, CNE2 and C666 NPC cell lines were cultured, as described previously (15). CNE1 and CNE2 cells are derived from well- and poorly-differentiated squamous carcinoma, and C666 is derived from undifferentiated carcinoma (15). The NPC cell lines were maintained in Roswell Park Memorial Institute-1640 medium (HyClone Laboratories, Inc., Logan, UT, USA), supplemented with $10 \%$ fetal bovine serum (HyClone Laboratories, Inc.) at $37^{\circ} \mathrm{C}$ in a humidified incubator containing $5 \% \mathrm{CO}_{2}$. The cell lines were provided by Professor Musheng Zeng (State Key Laboratory of Oncology in Southern China Cancer Institute, Sun Yat-sen University, Guangzhou, China). Once the cells reached $50 \%$ confluence $\left(3 \times 10^{5}\right.$ cells $)$, they were irradiated with UV, at a wavelength of $254 \mathrm{~nm}$, for $45 \mathrm{~min}$ in an ESCO biosafety cabinet (Esco Micro Pte Ltd., Singapore). The 2',7'-dichlorodihydrofluorescein diacetate and N-acetyl-L-cysteine (NAC) were purchased from Sigma-Aldrich (St. Louis, MO, USA).

Reverse transcription-quantitative polymerase chain reaction $(R T-q P C R)$. To quantify the expression levels of miR-9, the total RNA was extracted from the cells using TRIzol reagent (Omega Bio-Tek, Norcross, GA, USA). The total RNA (1 $\mu \mathrm{g})$ was reverse transcribed using Moloney Murine Leukemia Virus Reverse Transcriptase (Promega Corporation, Madison, WI, USA) and the products were used for qPCR analysis using SYBR Green PCR Master mix (Toyobo Life Science, Osaka, Japan), according to the manufacturer's instructions. ABI9700 and ABI7500 systems (Applied Biosystems Life Technologies, Foster City, CA, USA) were used to conduct PCR and qPCR, respectively. The forward primers for the miR-9 and U6 internal control were 5'-ACACTCCAGCTGGGTCTTTGGTTATCTAGCTG-3' and 5'-CTCGCTTCGGCAGCACA-3', respectively. The expression levels of miR-9 were measured in the various NPC cell lines at numerous time-points $(6,12$ and $24 \mathrm{~h}$ ) following radiation exposure. The expression levels of miR-9 in the cancer cells without radiation were considered the control. The primers were designed by the Land Co., Ltd., (Guangzhou, China). The PCR conditions were set as follows: $95^{\circ} \mathrm{C}$ for $5 \mathrm{~min}$, followed by 40 cycles of $95^{\circ} \mathrm{C}$ for $15 \mathrm{sec}, 65^{\circ} \mathrm{C}$ for $15 \mathrm{sec}$ and $72^{\circ} \mathrm{C}$ for $32 \mathrm{sec}$, and a final extension step at $72^{\circ} \mathrm{C}$ for $5 \mathrm{~min}$. The $2^{-\Delta \Delta \mathrm{Ct}}$ method was used to compare the miR-9 levels between different nasopharyngeal cells.

Western blotting and incubation with antibodies. The cells were washed twice in phosphate-buffered saline and dissolved in radioimmunoprecipitation assay buffer (Beyotime Institute of Biotechnology, Shanghai, China) for $15 \mathrm{~min}$. The cell lysates were then collected and centrifuged at $12,000 \mathrm{x}$ g for $15 \mathrm{~min}$ at $4^{\circ} \mathrm{C}$. Protein concentrations were determined using KeyGen BCA Protein Quantitation assay (cat. no. KGPBCA; Nanjing KeyGen Biotech Co. Ltd., Nanjing, China). The protein samples $(100 \mu \mathrm{g})$ were subjected to $7 \%$ sodium dodecyl sulfate-polyacrylamide gel electrophoresis, transferred onto nitrocellulose membranes (EMD Millipore, Billerica, MA, USA), blocked with 5\% fat-free milk (Dingguo Biotechnology Co., Ltd., Beijing, China) and incubated with the following primary antibodies: Polyclonal rabbit anti-human E-cadherin (1:100, cat. no. BA0474; Boster Biotechnology Co., Ltd., Wuhan, China) and polyclonal rabbit anti-human GAPDH (1:500; cat. no. sc-25778; Santa Cruz Biotechnology, Inc., Santa Cruz, CA, USA), at $4^{\circ} \mathrm{C}$ overnight. Protein detection was performed using horseradish peroxidase-conjugated goat anti-rabbit secondary antibodies (1:2,000; cat. no. KGAA35; Nanjing KeyGen Biotech Co., Ltd., Nanjing, China) and enhanced chemiluminescence reagents (Nanjing KeyGen Biotech Co., Ltd.).

RNA oligoribonucleotides and cell transfection. An RNA duplex with a forward sequence of 5'-UCUUUGGUUAUCUA GCUGUAUGA-3' was used to mimic endogenous mature miR-9 molecules. The small interfering RNA (siRNA) targeting human E-cadherin mRNA was designed, as previously described, using the sequence of 5'-CAGACAAAGACCAGGACUATT-3' (16). The control RNA duplex (negative control) for the miR-9 mimics and the siRNA was not homologous to any known gene sequences. All RNA oligoribonucleotides were purchased from Genepharma (Shanghai, China). Once the cells reached $\sim 60 \%$ confluence, they were transiently transfected using Lipofectamine 2000 (Invitrogen Life Technologies, Carlsbad, CA, USA), according to the manufacturer's instructions.

Colony formation assay. Following transfection and incubation for $48 \mathrm{~h}$, the cells were irradiated with UV for $45 \mathrm{~min}$. The cells were subsequently trypsinized $(0.25 \%$ trypsin-EDTA; Invitrogen Life Technologies), collected and cultured in a fresh six-well plate at a density of 100 cells per well. Following 10 days incubation, the cells were fixed with methanol (Dingguo Biotechnology Co., Ltd.) for $10 \mathrm{~min}$ and stained with $0.1 \%$ crystal violet (Dingguo Biotechnology Co., Ltd.) for $15 \mathrm{~min}$. The number of colonies were counted under an inverted microscope (CKX41; Olympus Corporation, Tokyo, Japan) and the data were evaluated by statistical analyses (SPSS version 13.0; SPSS Inc., Chicago, IL, USA).

Apoptosis assay. The levels of UV-induced apoptosis were evaluated $48 \mathrm{~h}$ after transfection and UV irradiation for $45 \mathrm{~min}$. Annexin V-fluorescein isothiocyanate conjugate $(5 \mu \mathrm{l})$ and propidium iodide solution $(5 \mu \mathrm{l})$ were added to the cell suspension for the apoptosis assay, according to the manufacturer's instructions (Nanjing KeyGen Biotech Co., Ltd.). The stained cells were analyzed using a flow cytometer (FACSCalibur; BD Biosciences, Franklin Lakes, NJ, USA).

Alkaline comet assay. To detect DNA damage in individual cells following exposure to UV radiation, DNA damage 
was assessed using a single-cell gel electrophoresis assay. Alkaline conditions were generated with $1 \mathrm{mmol} / \mathrm{l}$ EDTA and $300 \mathrm{mmol} / \mathrm{l} \mathrm{NaOH}$ for electrophoresis. A total of $48 \mathrm{~h}$ post-transfection and irradiation with UV (45 min), the cells were embedded in agarose, and lysis and electrophoresis were performed under alkaline conditions according to the manufacturer's protocol (Nanjing KeyGen Biotech Co., Ltd.). The fluorescence images were captured using a fluorescence microscope system (IX71; Olympus Corporation). The olive tail moment was measured from the comet images to reflect the DNA damage, as described previously (17).

Intracellular ROS assay. The determine the levels of intracellular ROS in the cells, $20 \mu \mathrm{M}$ 2', 7'-dichlorodihydrofluorescin diacetate (Sigma-Aldrich) was added to the culture medium $48 \mathrm{~h}$ after transfection, and incubated at $37^{\circ} \mathrm{C}$ for $20 \mathrm{~min}$. The cells were subsequently irradiated with UV for $45 \mathrm{~min}$ and the levels of fluorescence were measured using a Synergy HT microplate reader (BioTek Instruments Inc., Winooski, VT, USA) at a filter pair excitation of 485/20 and an emission of 528/20 (8).

Glutathione assay. The levels of total glutathione and reduced glutathione were detected using a GSH and GSSG Assay kit (Beyotime Institute of Biotechnology) via the benzoic acid method, following UV exposure for $45 \mathrm{~min}$. The cells were treated according to the manufacturer's instructions and measurements were recorded using a microplate reader (Synergy HT, BioTek Instruments Inc.) at $412 \mathrm{~nm}$ (18).

NAC exerts its protective effect predominantly as a glutathione precursor in various models with disorders associated with oxidative stress, by directly scavenging ROS (19). To further define the role of glutathione in the modulation of radiosensitivity by miR-9, the cells were pre-treated with $1 \mathrm{mM} \mathrm{NAC}$ for $4 \mathrm{~h}$ prior to intracellular ROS analysis.

Statistical analysis. Unless otherwise stated, the data are expressed as the mean \pm standard deviation of at least three independent experiments. Statistical analyses were conducted using SPSS version 13.0. Significance was determined using Student's t-test and $\mathrm{P}<0.05$ was considered to indicate a statistically significant difference.

\section{Results}

Kinetics of the expression of miR-9 following exposure to $U V$. The present study examined whether miR-9 regulated the sensitivity of NPC cells to UV-induced damage, and investigated the potential mechanisms underlying the radiosensitivity of NPC cells. The results demonstrated no significant changes in the expression levels of miR-9 in the different NPC cell lines (Fig. 1A). The expression levels of miR-9 were measured in different NPC cell lines at several time-points following exposure to radiation, ranging between 1 and $24 \mathrm{~h}$. Increased expression levels of miR-9 were observed in the well- and poorly-differentiated tumor cells in response to UV exposure (Fig. 1B). The induction of miR-9 following UV radiation was transient and was particularly marked in the CNE2 cells.

miR-9 suppresses the radiosensitivity of CNE2 cells to $U V$. The previously reported significant upregulation in the expression

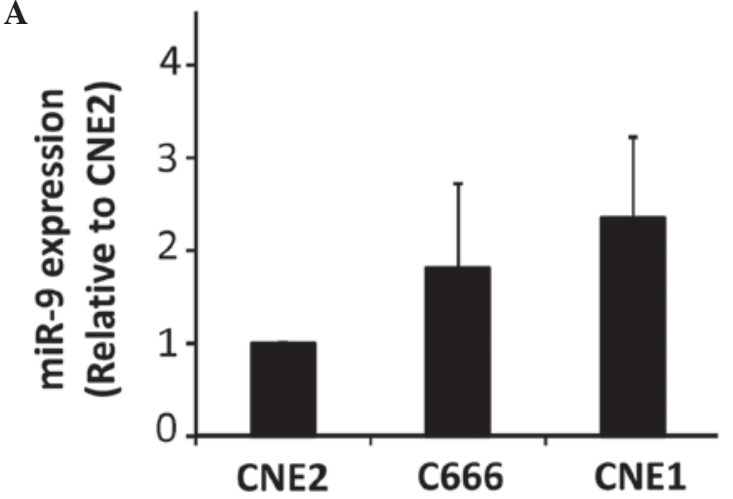

B

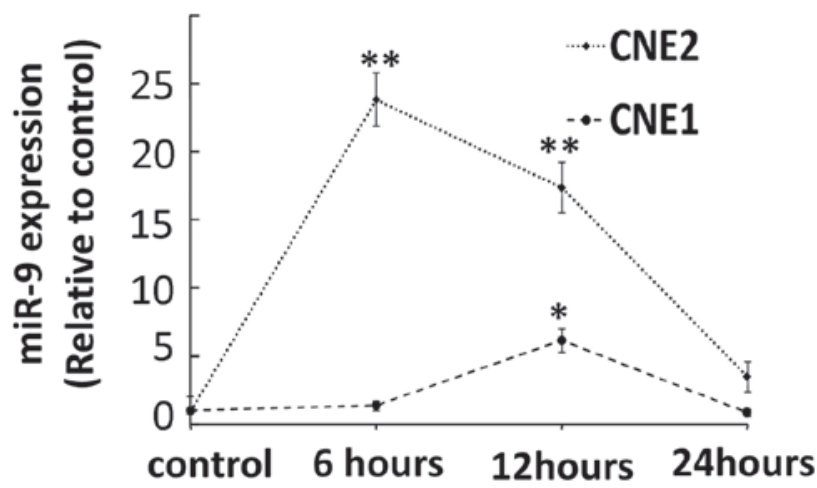

Figure 1. Regulation of miR-9 in response to exposure to UV radiation. (A) Expression levels of miR-9 were measured by reverse transcription-quantitative polymerase chain reaction in three NPC cell lines. No significant changes in the expression levels of miR-9 were observed in the different NPC cell lines. (B) Induction of miR-9 in response to UV radiation in the CNE2 and CNE1 cells. The data are expressed as the mean \pm standard deviation. ${ }^{*} \mathrm{P}<0.05$ and ${ }^{* *} \mathrm{P}<0.01$, as compared with the control cells. miR, microRNA; NPC, nasopharyngeal carcinoma; UV, ultraviolet.

of miR-9 in CNE2 cells following exposure to UV radiation prompted the present study to investigate the role of miR-9 in radiosensitivity. The colony forming capacities of the cells were assessed following exposure to UV radiation in the cells transfected with the miR-9 mimics. The results demonstrated that the CNE2 cells transfected with the miR-9 mimic exhibited an increased number of colonies following UV radiation compared with the control cells ( $\mathrm{P}<0.01$; Fig. 2A), suggesting that miR-9 inhibited the radiosensitivity of CNE2 cells. By contrast, no miR-9-induced increase in the clonogenic potential of the CNE1 cells was observed.

Effects of miR-9 on UV-induced apoptosis and DNA damage. Ionizing radiation causes severe cellular damage by disrupting the DNA integrity indirectly by forming intracellular free radicals (3). To determine whether miR-9 regulates cellular damage in response to $\mathrm{UV}$, the present study examined the extent of apoptosis in cells overexpressing miR-9. The results demonstrated that the CNE2 cells transfected with the miR-9 mimics exhibited decreased apoptosis compared with the control cells $(\mathrm{P}<0.01$; Fig. $2 \mathrm{~B}$ and $\mathrm{C})$. In addition, by performing a single-cell gel electrophoresis assay under alkaline conditions, the extent of DNA damage following irradiation in the CNE2 cells transfected with the miR-9 mimics was found to be lower compared with that observed in the control cells $(\mathrm{P}<0.001$; Fig. 2D). miR-9 failed to protect 
A

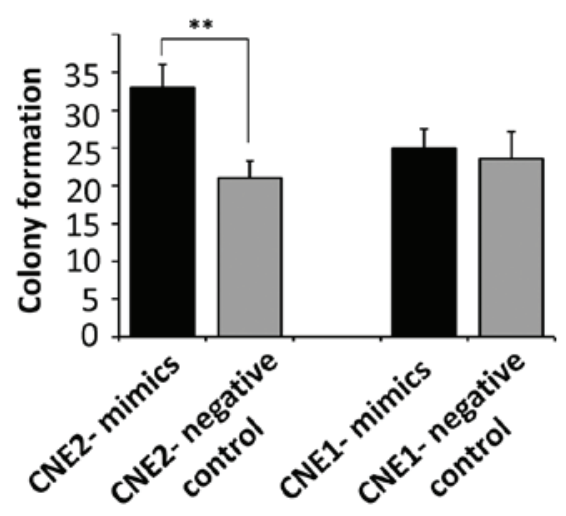

C

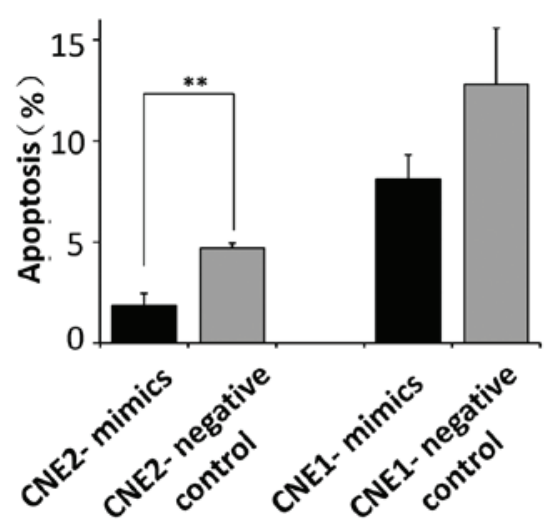

B
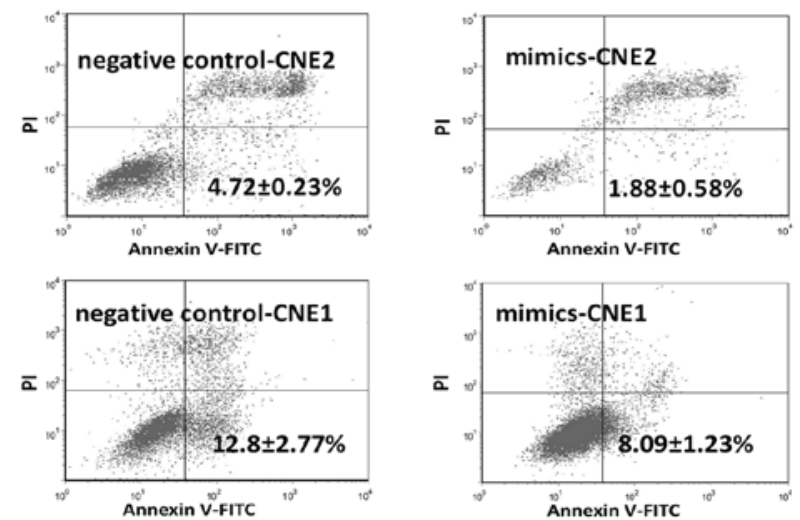

D

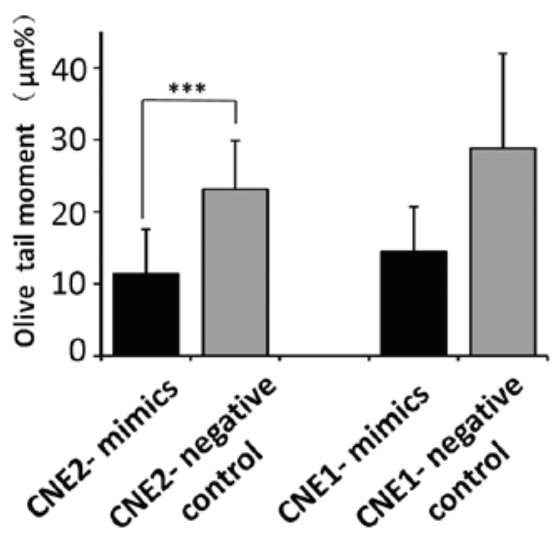

Figure 2. miR-9 suppresses the sensitivity of CNE2 cells to UV radiation. (A) Colony forming capacity following exposure to UV was assessed in cells transfected with miR-9 mimics. (B and C) Analysis of UV-induced apoptosis in cells transfected with miRs, as indicated. (D) Effects of miR-9 on DNA damage, assessed using an alkaline comet assay. The data are expressed as the mean \pm standard deviation $\left(\mathrm{n}=50 ;{ }^{* *} \mathrm{P}<0.01\right.$ and ${ }^{* * * *} \mathrm{P}<0.001$, compared with the control). miR, microRNA; UV, ultraviolet; PI, propidium iodide; FITC, fluorescein isothiocyanate.

the CNE1 cells from irradiation-induced apoptosis and did not affect the DNA damage response, consistent with its inability to alter the clonogenic potential in these cells.

ROS levels in tumor cells following exposure to UV radiation. Radiation induces severe cellular damage through the generation of ROS, which are controlled by free radical scavengers, including glutathione. No significant increase was observed in the production of ROS in tumor cells transfected with the miR-9 mimics (Fig. 3A). However, our previous study demonstrated that NPC cells with silenced expression of miR-9 produced lower levels of glutathione (11). Since miR-9 protected the CNE2 cells from UV radiation (Fig. 2), the effect of miR-9 on glutathione, which is important in protecting tumor cells from ROS following exposure to UV radiation, was assessed. The cells transfected with the miR-9 mimics exhibited significant increases in the total glutathione levels compared with the control CNE2 $(\mathrm{P}<0.01)$ and $\mathrm{CNE} 1$ cells $(\mathrm{P}<0.05$; Fig. $3 \mathrm{~B})$. In addition, the cells transfected with the miR-9 mimics produced more reduced glutathione compared with the control CNE1 cells $(\mathrm{P}<0.05)$. However, miR-9 had no significant effect on the levels of reduced glutathione in the CNE2 cells (Fig. 3C).

The analyses revealed significant variation in the total glutathione concentration regulated by miR-9 in NPC cells. Since NAC exerts its protective effect predominantly as a glutathione precursor in various models of oxidative stress, the present study used NAC to pharmacologically increase cellular ROS defenses, to elucidate the contribution of glutathione, regulated by miR-9, in UV-induced radiosensitivity. The results demonstrated that the levels of ROS following exposure to UV radiation were inhibited by the antioxidant, NAC, in the CNE2 cells $(\mathrm{P}<0.001$; Fig. 3D), which indicated a role for glutathione in resistance against UV exposure in CNE2 cells.

miR-9 does not regulate radiosensitivity through modulation of the expression of E-cadherin. Decreased expression levels of E-cadherin were observed in the NPC cells 24 and $48 \mathrm{~h}$ following radiation exposure (Fig. 4A and B), which suggested that the expression of E-cadherin may regulate the radiosensitivity of NPC cells to UV. In addition, the levels of E-cadherin were decreased in the CNE2 cells transfected with the miR-9 mimics and, as expected, in the cells transfected with E-cadherin-specific siRNA (Fig. 4C). To determine whether miR-9 regulated radiosensitivity by targeting the expression of E-cadherin in the CNE2 cells, the expression of E-cadherin was silenced using siRNA to examine the effect of E-cadherin deficiency on the radiosensitivity of the tumor cells.

No significant changes in the colony forming capacity or levels of apoptosis were observed between the control cells and the cells transfected with siRNA targeting E-cadherin 
A

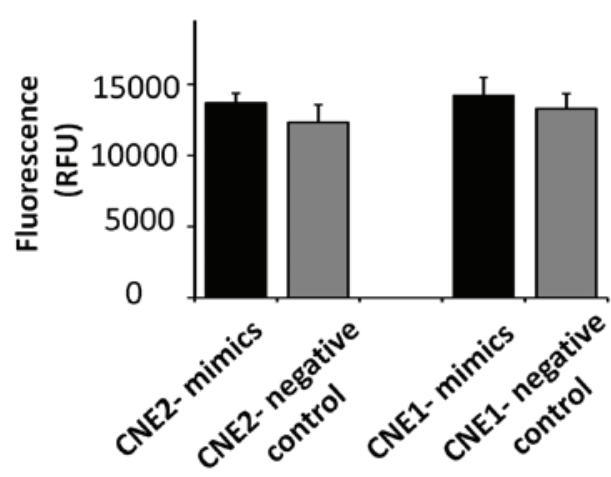

C

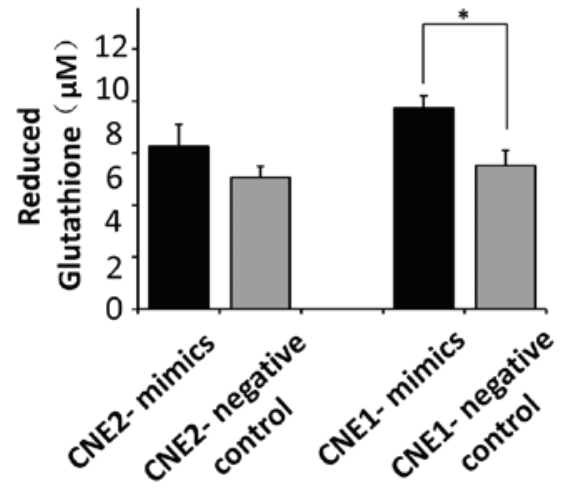

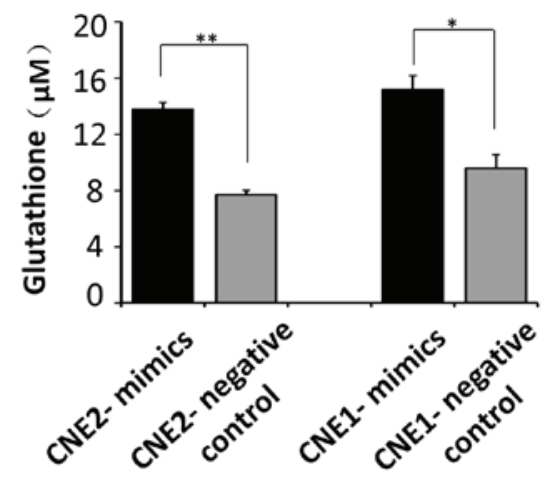

D

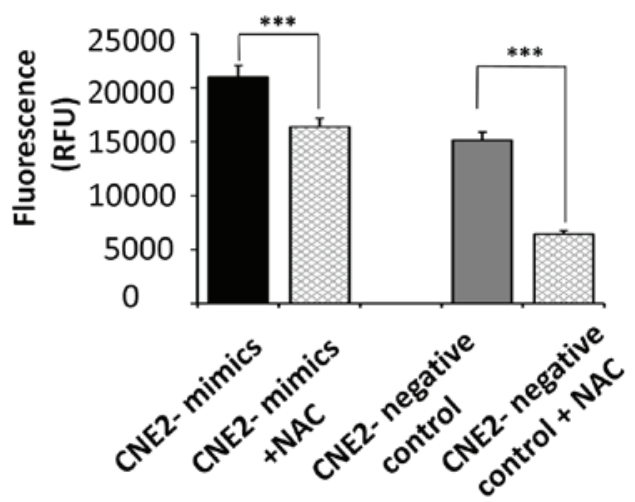

Figure 3. Characterization of CNE2 and CNE1 cells transfected with miR-9 following exposure to UV radiation. (A) Changes in the production of ROS regulated by miR-9 following exposure to UV radiation $(n=4)$. (B and C) Effects of miR-9 on the levels of total and reduced glutathione following exposure to UV radiation. (D) Total levels of ROS, following exposure to UV radiation, were inhibited by the antioxidant, NAC. The data are expressed as the mean \pm standard deviation ( $\mathrm{n}=4 ;{ }^{*} \mathrm{P}<0.05 ;{ }^{* * *} \mathrm{P}<0.01 ;{ }^{* * *} \mathrm{P}<0.001$ ). UV, ultraviolet; ROS, reactive oxygen species; NAC, N-acetyl-L-cysteine; RFU, relative fluorescence units.

A

E-cadherin

GAPDH

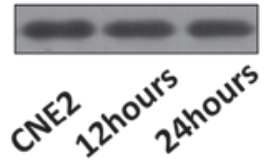

D

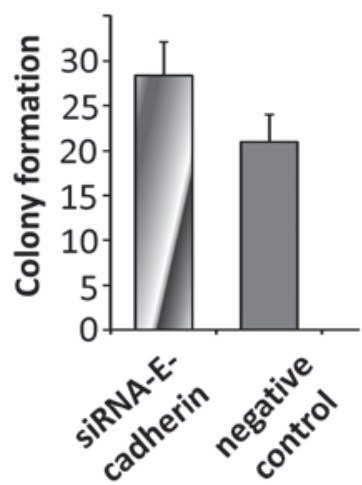

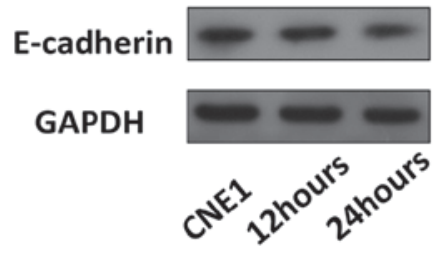

$\mathbf{E}$

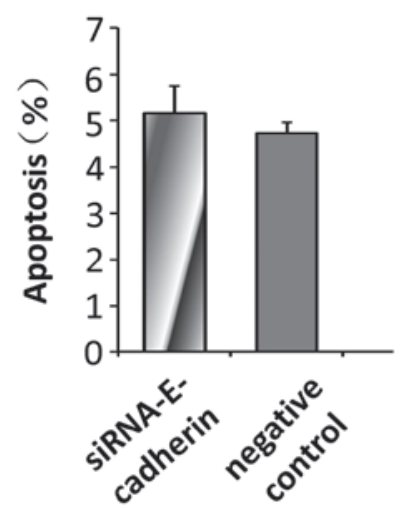

C

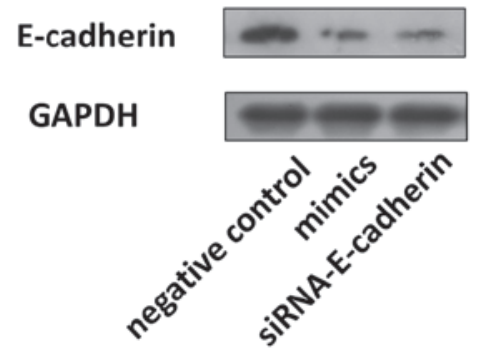

F

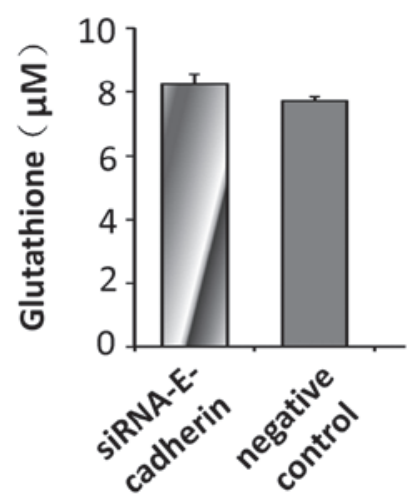

Figure 4. Radiosensitivity of CNE2 cells is not regulated by E-cadheran. (A and B) Expression levels of E-cadherin were decreased in the CNE2 and CNE1 cells following exposure to UV radiation. (C) Expression of E-cadherin in CNE2 cells transfected with miR-9 mimics or siRNA targeting E-cadherin. (D) Colony forming capacity following exposure to UV radiation was evaluated in cells transfected with E-cadherin specific siRNA. (E) UV-induced apoptoticrate was analyzed in cells transfected with E-cadherin siRNA. (F) Effects of E-cadherin siRNA on the levels of total glutathione following exposure to UV radiation. The data are expressed as the mean \pm standard deviation. UV, ultraviolet; si, small interfering; miR, microRNA. 
(Fig. 4D and E). In the cells transfected with E-cadherin siRNA, no significant difference in the production of glutathione was observed compared with the control CNE2 cells (Fig. 4F).

These results demonstrated that miR-9 suppressed the radiosensitivity of the cells to UV through its effects on glutathione, rather than its ability to modulate the expression of E-cadherin.

\section{Discussion}

The mechanisms underlying NPC radiosensitivity remain to be fully elucidated. The formation of ionizing radiation-induced ROS is associated with radiation-induced apoptosis and necrosis. The expression levels of several miRNAs are significantly altered in response to radiation treatment, and changes in the expression levels of miRNAs, including miR-17, may be involved in DNA damage and the production of $\operatorname{ROS}(8,20)$. miRNAs are, therefore, suitable candidates for modulating the radiosensitivity of cancer cells. UV-induced ROS have been reported to trigger cellular damage, and our previous study revealed that miR-9 promotes the UV-induced production of ROS (11). The present study investigated the sensitivity of NPC to UV. The potential role of miRNAs in the protection of tumor cells from radiosensitivity and the production of ionizing radiation-induced ROS have not been previously investigated in NPC cells. The present study demonstrated that CNE2 cells overexpressing miR-9 exhibited less DNA damage and increased levels of total glutathione. These cells were found to exhibit decreased apoptosis and increased clonogenic potential in response to radiation.

miR-9 appears to have varying effects on proliferation and apoptosis in different types of cancer cell. miR-9 is overexpressed in caudal type homeobox 2-negative gastric cancer cells, and knockdown of miR-9 inhibits the proliferation of human gastric cancer cells (21). By contrast, the overexpression of miR-9 also suppresses proliferation of different lines of gastric cancer cells $(22,23)$. UV-induced production of ROS and DNA damage modulates growth inhibition and apoptosis by altering the ratios of Bax/Bcl-2 and other signaling pathways (24). The data from the present study demonstrated that miR-9 protected the tumor cells from UV-induced cell damage. In the CNE2 cells, overexpression of miR-9 increased the clonogenic potential and suppressed the apoptosis induced by UV. By contrast, acute knockdown of miR-9 has no effects on the survival of human neural progenitor cells or tumor cells (25). The production of ROS can also result in DNA damage due to the accumulation of $\mathrm{p} 53$ and the formation of 8-OH guanine from UV irradiation (10). In addition to exhibiting lower levels of ROS, certain cancer stem cells develop less DNA damage following irradiation (3).

As the biological effects of ionizing radiation are largely mediated by free radicals, the present study examined the effect of miR-9 on the production of ROS and free radical scavengers. UV causes cellular damage by producing ROS species, including $\mathrm{O}^{2}, \mathrm{O}^{2-}$ and $\mathrm{H}_{2} \mathrm{O}_{2}(10)$. The present study demonstrated that NPC cells with silenced expression of miR-9 produced lower levels of glutathione following exposure to UV radiation. Since the overexpression of miR-9 revealed no increased production of ROS following exposure to UV radiation, the present study focused on glutathione, a critical cellular reducing agent, which is implicated in regulating mutagenic mechanisms, DNA synthesis, growth and multidrug and radiation resistance (26). In addition, increased glutathione biosynthesis in a subset of cancer stem cells has been observed to contribute to tumor radiosensitivity (3). The results of the present study revealed changes in the total and reduced levels of glutathione regulated by miR-9 in the different NPC cells. The upregulation of the total glutathione was important in rescuing tumor cells from irradiation-induced apoptosis. The protective effect of miR-9 was more marked in the CNE2 cells compared with the CNE1 cells, however, no changes were observed in reduction of glutathione in the CNE2 cells. These data suggested that miR-9 regulated the UV-exposure-induced radiation response, at least in part, through its effect on glutathione. The mechanism whereby miR-9 regulates glutathione levels remains to be elucidated. In the present study, no correlation was observed between miR-9 and glutamate-cysteine ligase, which is critical in GSH biosynthesis.

miR-9 has been demonstrated to have different effects on the expression levels of E-cadherin in different types of cancer cells (27). The present study demonstrated that miR-9 downregulated the expression of E-cadherin in the CNE2 cells, and that miR-9 protected the CNE2 cells following exposure to UV radiation. Although E-cadherin has been demonstrated to regulate chemoresistance and radioresistance of cancer cells, silencing of the expression of E-cadherin had no effect on the response of the NPC cells to UV or on alter the levels of total glutathione. The expression of E-cadherin is regulated by ubiquitination and multiple signaling pathways, therefore, it is likely that several factors are involved in the downregulation of E-cadherin following irradiation in NPC cells (28).

The present study demonstrated that the overexpression of miR-9 suppressed the radiosensitivity of CNE2 cells, as demonstrated by an increased number of colonies, reduced levels of apoptosis and reduced DNA damage following UV radiation. In addition, miR-9 was found to exert it effects through glutathione, rather than through its effect on the expression of E-cadherin, in the CNE2 cells. Taken together, these findings suggested that miR-9 may be a potential therapeutic target in NPC therapy.

\section{Acknowledgements}

This study was supported by the Natural Science Foundation of Guangdong Province (no. 10251008901000023).

\section{References}

1. Preston RJ: Radiation biology: concepts for radiation protection. Health Phys 88: 545-556, 2005.

2. Wei WI and Sham JS: Nasopharyngeal carcinoma. Lancet 365: 2041-2054, 2005.

3. Diehn M, Cho RW, Lobo NA, Kalisky T, Dorie MJ, Kulp AN, Qian D, Lam JS, Ailles LE, Wong M, Joshua B, et al: Association of reactive oxygen species levels and radioresistance in cancer stem cells. Nature 458: 780-783, 2009.

4. Wang J, Wakeman TP, Lathia JD, Hjelmeland AB, Wang XF, White RR, Rich JN and Sullenger BA: Notch promotes radioresistance of glioma stem cells. Stem Cells 28: 17-28, 2010.

5. Bartel DP: MicroRNAs: genomics, biogenesis, mechanism and function. Cell 116: 281-297, 2004. 
6. Ilnytskyy Y, Zemp FJ, Koturbash I and Kovalchuk O: Altered microRNA expression patterns in irradiated hematopoietic tissues suggest a sex-specific protective mechanism. Biochem Biophys Res Commun 377: 41-45, 2008.

7. Josson S, Sung SY, Lao K, Chung LW and Johnstone PA: Radiation modulation of microRNA in prostate cancer cell lines. Prostate 68: 1599-1606, 2008.

8. Simone NL, Soule BP, Ly D, Saleh AD, Savage JE, Degraff W, Cook J, Harris CC, Gius D and Mitchell JB: Ionizing radiation-induced oxidative stress alters miRNA expression. PLoS One 4: e6377, 2009.

9. Arora H, Qureshi R, Jin S, Park AK and Park WY: miR-9 and let-7 g enhance the sensitivity to ionizing radiation by suppression of NFкB1. Exp Mol Med 43: 298-304, 2011.

10. Ravanat JL, Douki T and Cadet J: Direct and indirect effects of UV radiation on DNA and its components. J Photochem Photobiol B 63: 88-102, 2001.

11. Zheng CP, Han L, Hou WJ, Wen YH, Fu R, Ma RQ and Wen WP: Inhibition of micro RNA-9 expression promotes UV-induced ROS damage in nasopharyngeal carcinoma cells. Zhonghua Er Bi Yan Hou Tou Jing Wai Ke Za Zhi 48: 668-672, 2013 (In Chinese).

12. Theys J, Jutten B, Habets R, Paesmans K, Groot AJ, Lambin P, Wouters BG, Lammering $\mathrm{G}$ and Vooijs M: E-Cadherin loss associated with EMT promotes radioresistance in human tumor cells. Radiother Oncol 99: 392-397, 2011.

13. Xie LQ, Bian LJ, Li Z, Li Y, Li ZX and Li B: Altered expression of E-cadherin by hepatocyte growth factor and effect on the prognosis of nasopharyngeal carcinoma. Ann Surg Oncol 17: 1927-1936, 2010.

14. Ma L, Young J, Prabhala H, Pan E, Mestdagh P, Muth D, Teruya-Feldstein J, Reinhardt F, Onder TT, Valastyan S, et al: $\mathrm{miR}-9$, a MYC/MYCN-activated microRNA, regulates E-cadherin and cancer metastasis. Nat Cell Biol 12: 247-256, 2010.

15. Lu J, He ML, Wang L, Chen Y, Liu X, Dong Q, Chen YC, Peng Y, Yao KT, Kung HF and Li XP: MiR-26a inhibits cell growth and tumorigenesis of nasopharyngeal carcinoma through repression of EZH2. Cancer Res 71: 225-233, 2011.

16. Hayashida Y, Honda K, Idogawa M, Ino Y, Ono M, Tsuchida A, Aoki T, Hirohashi S and Yamada T: E-cadherin regulates the association between beta-catenin and actinin-4. Cancer Res 65: $8836-8845,2005$
17. Undeğer U, Zorlu AF and Basaran N: Use of the alkaline comet assay to monitor DNA damage in technicians exposed to low-dose radiation. J Occup Environ Med 41: 693-698, 1999.

18. Vandeputte C, Guizon I, Genestie-Denis I, Vannier B and Lorenzon G: A microtiter plate assay for total glutathione and glutathione disulfide contents in cultured/isolated cells: performance study of a new miniaturized protocol. Cell Biol Toxicol 10: 415-421, 1994.

19. Zhang F, Lau SS and Monks TJ: The cytoprotective effect of $\mathrm{N}$-acetyl-L-cysteine against ROS-induced cytotoxicity is independent of its ability to enhance glutathione synthesis. Toxicol Sci 120: 87-97, 2011.

20. Weidhaas JB, Babar I, Nallur SM, Trang P, Roush S, Boehm M, Gillespie E and Slack FJ: MicroRNAs as potential agents to alter resistance to cytotoxic anticancer therapy. Cancer Res 67: 11111-11116, 2007.

21. Rotkrua P, Akiyama Y, Hashimoto Y, Otsubo T and Yuasa Y: MiR-9 down-regulates CDX2 expression in gastric cancer cells. Int J Cancer 129: 2611-2620, 2011.

22. Tsai KW, Liao YL, Wu CW, Hu LY, Li SC, Chan WC, Ho MR, Lai CH, Kao HW, Fang WL, Huang KH and Lin WC: Aberrant hypermethylation of miR-9 genes in gastric cancer. Epigenetics 6: 1189-1197, 2011

23. Zheng L, Qi T, Yang D, Qi M, Li D, Xiang X, Huang K and Tong Q: microRNA-9 suppresses the proliferation, invasion and metastasis of gastric cancer cells through targeting cyclin D1 and Ets1. PLoS One 8: e55719, 2013.

24. Schmitt CA and Lowe SW: Apoptosis and therapy. J Pathol 187: 127-137, 1999.

25. Yuva-Aydemir Y, Simkin A, Gascon E and Gao FB: MicroRNA-9: Functional evolution of a conserved small regulatory RNA. RNA Biol 8: 557-564, 2011.

26. Estrela JM, Ortega A and Obrador E: Glutathione in cancer biology and therapy. Crit Rev Clin Lab Sci 43: 143-181, 2006.

27. Liu S, Kumar SM, Lu H, Liu A, Yang R, Pushparajan A, Guo W and Xu X: MicroRNA-9 up-regulates E-cadherin through inhibition of NF- $\kappa B 1-S n a i l 1$ pathway in melanoma. J Pathol 226: 61-72, 2012.

28. Fujita Y, Krause G, Scheffner M, Zechner D, Leddy HE Behrens J, Sommer T and Birchmeier W: Hakai, a c-Cbl-like protein, ubiquitinates and induces endocytosis of the E-cadherin complex. Nat Cell Biol 4: 222-231, 2002. 